\title{
The convergence of Social Networking, Mobile and Virtual Learning Environments
}

\author{
Felix P. Rante, Abraham G. Campbell \\ University College Dublin, Ireland
}

\begin{abstract}
Eight seconds, that's the attention span of the present generation. With all the distractions particularly from social media such as social networking websites, a formidable platform for influencing people, and mobile technology, a very efficient vehicle to get your message across your audience; how could the academia encourage students to take advantage of many useful features of their Virtual Learning Environment (VLE) and be active learners. This paper is about designing a modern VLE for the Social-Mobile centric age and today's learners. The primary contribution of this research work is, it initiates a discussion on leveraging Social Networking and Mobile Technology in Education, highlighting the needs to rethink and redesign the future of education amid the Social-Mobile centric world that we are in today. Specifically, this research paper offers a new set of quantitative and qualitative data, technical discussion on how to integrate Social Networking features in a VLE using Mobile Technology as a delivery channel. A review of related literature, and a Social Mobile VLE prototype using Moodle and Android App.
\end{abstract}

\section{Introduction}

There is no argument, communication is vital in the learning process [1]. Human learn by communicating with each other either using words, signs and other similar medium. In schools, the common practice to educate students is via lecture sessions and other collaborative activities involving communication. Attendance to a class used to be a must for students to learn, until distance education was introduced. The introduction of Virtual Learning Environment (VLE) such as Blackboard and Moodle was disruptive, it changed many aspects of both distance and campus-based education for the better. VLEs provide educators a central storage for school materials and allow them to share the materials with their students remotely and instantly. VLEs allow students to access learning materials online 24/7 providing them freedom to study on their own time and space [2]. VLEs are now heavily deployed particularly in the Universities and Colleges. Educators and Students alike view VLE favourably as it offers functionalities that make their academic experience better, students can now concentrate on listening and other learning activities and are no longer required to take long notes; educators on the other hand is now able to concentrate on improving learning materials (already in VLE) and answering new questions via Forum. Research shows that VLE are still popular amongst learners, however, while students social media engagement is off the charts, the same cannot be said with VLE, students' VLE engagement are declining. The challenge to the academia is how to encourage students to be active learners, how to motivate them to spend more time in their VLEs, actively post and answer questions, and regularly interact with their teachers and fellow students; make students actively use their VLE like they actively use Facebook and other social networking sites. This research is about designing a modern Virtual Learning Environment, a learning environment that is designed for today's learner: a VLE in the social-mobile centric age.

\section{Background}

Many educational institutions have long embraced technology's vital role in education and for many years employed online learning in their teaching methodologies. For example, the UK Open University, for instance, had since 1970's used computer for learning [5]. Using the Internet to deliver learning materials such as live video demonstration, audio lectures and other educational materials facilitate learning; Polisca [3] supports this. The introduction of Virtual Learning Environment such as Moodle, changed the landscape of Education. It made education more accessible to more people via online or distance learning. Both Educators and Learners agree that VLE positively impacts academic experience [5] [7] [8].

The human average attention span had dropped from 12 seconds to eight [9], the shortest ever recorded and is comparable to a goldfish. In the age where traditional media companies no longer have monopoly on content production and distribution, and where anyone and everyone, via various social networking platforms (e.g Facebook, YouTube) can publish high quality content such as a video blog, entertainment channel, a tutorial websites among others, competing for people's attention is becoming a challenge. In the era where people, students in particular, have access to a very powerful device that allows them to instantly get what they want and need, would they still willing to go the laboratory or sit in front of their computer to access their VLE?

While VLE's supremacy in the academia has yet to be challenged, its contemporaneity is in question. Research shows that students VLE engagement seem to be declining. So the question is, in the socialmobile centric age, how could the academia 
encourage students to engage with their VLE and use the collaboration tools such forum the way they use Facebook, Twitter, Whatsup and other popular social networking platforms. Alternatives such as moving the class room entirely in Virtual Reality have been explored [21] but a blended environment using every available tool is preferred.

\subsection{What's wrong with existing VLEs (Moodle)?}

Justing Ferriman, the co-founder and CEO of LearnDash, a WordPress LMS for major Universities, acknowledges the popularity of Moodle but argue that it is decreasing and is becoming irrelevant for two reasons: (1) It is ugly and (2) it is not user-friendly [10]. John Wooding, the founding director of JWGecko, thinks that there was nothing wrong with Moodle, except that Moodle had limited Web Services that is required for third party Learning Management System (LMS) integration and that Moodle was way behind a comparable nonopen source LMS [11]. While experts' opinion of Moodle varies, nobody refutes its popularity, and being the most popular and open VLE available, Moodle will be used in building a sample Social Mobile VLE prototype.

\subsection{The rise of Social Networking and the Mobile Centric Age}

The technological revolution of the $21^{\text {st }}$ century (availability of faster and cheaper broadband, Web2.0, cloud computing among others) had transformed numerous things into something arguably better. The most visible changes are in socializing and networking space. The introduction of online Social Networking Sites (SNSs) such as MySpace, Bebo, Facebook, YouTube, Instagram, Twitter among others reinvented socializing and networking; from a traditional face-face event, these activities can now be done in the digital space. SNSs are seen as a 'global consumer phenomenon' with an exponential rise in usage within the last few years [12]. It could be argued that the colossal increased activity in the social media is due to the narcissistic personality of many SNSs users. In fact, this argument is supported by the study on Narcissism and Social Networking Web Sites conducted by Buffardi and Campbell [13].

Satya Nadella, current Microsoft's CEO, on his keynote speech in the 2015 Microsoft's Worldwide Partner Conference (WPC), shared Microsoft's vision for the future, it is a cloud and mobile-centric one. Microsoft strategy is: "mobile-first, cloud-first". Satya believe that in the "mobile-first, cloud-first world", the mobility of experience is of utmost important [14], importantly mobile technology wasn't accessible to a lot of people due to its expensive price tag. For instance, a Motorola DynaTAC cellular phone, costs nearly $\$ 4 \mathrm{~K}(\$ 9 \mathrm{~K}$ in today's money) [16]. Now it's changed, mobile devices are really mobile, they cost a lot cheaper and they can do a lot more things. This research paper attempts to explore the effect of making these collaboration tools more accessible to students using Social Networking and Mobile Technology.

\section{Research Methods}

Educators and learners are the primary users of Virtual Learning Environment (VLE), these two groups are supposed to be the target users and therefore have to be involved in designing future VLEs and developing the existing ones. Hence, it is necessary to have the opinions of both groups consulted, and utilise several approaches in gathering these inputs to ensure a reliable finding. This section describes the various research philosophies, approaches and strategies employed in the research. This section also explains the relevance of the survey design, ethics compliance and participant's demographics.

\subsection{Research Philosophy}

The decreasing attention span of the younger generation makes it a more urgent task for VLE designers to compete for student's attention. The prevalent culture among the younger generation today revolves around social networking, instant gratification, accessibility, UX and everything mobile. VLEs made quality education accessible, it makes it possible for schools to offer distance education and online courses (e.g. Oxford, Harvard and other highly regarded Schools offer online courses). Perhaps for the $10 \%$ who are highly motivated learners, the development can stop at this point, learners who are highly motivated don't need an additional stimulant, but for the average students, it is a different story. Is it worthwhile to ask whether in a Social-Mobile centric world, is it enough for schools to have a VLE? Or is there a need to make it more accessible? To understand what students think of current VLEs the positivist philosophy is employed. Presumably, given that all variables are equal when it comes to understanding what the majority thinks about VLEs, positivist is the best methodology. Regarding the question about the effect of making VLE adapt with the present popular culture while this can easily be answered in the affirmative, this is an open question and perhaps depending on the execution (e.g. integration approach, timing), the answer could either be positive or negative. To improve the reliability of the result the pragmatist's view was adopted in the study. The positivist philosophy was employed to 
answer straightforward questions; the experts dealt with the qualitative questions.

\subsection{Research Approach}

The research questions and objectives drive the overall research approach. The deductive approach is employed to frame the structure of the study. The research question which is about exploring the convergence of social networking, mobile technology and virtual learning platform dictates that the overall approach is inductive.

The study started with some general assumptions; an exploratory study was conducted to validate and polish these assumptions. After the study has been properly structured and focus achieved, the research activity continued in a descriptive mode; a number of related learning theories, learning environments, and latest technologies and the modern culture were analysed and incorporated in the study. Finally, all significant data independently gathered from various sources were evaluated, tabulated and interpreted. The result of the analysis done on the data then became the basis of the conclusion and recommendations.

\subsection{Research Strategies}

The study is about exploring the effect of making virtual learning more accessible via mobile social networking. It seeks to find out the benefits of integrating the best of the bests; the prevalent culture which is social networking, the widely used electronic device which is mobile-phone and tablets, also means mobile technology and education platform that is the VLE. The case study initially involved the following activities (i) Develop a social-mobile app to expose VLE services (ii) Develop new services to compliment existing Moodle services (e.g. Communicating to third party platform). (iii) Deploy the services and application to an existing operational Moodle installation, and (iv) Have a set of students evaluate the application and provide their feedback. In an explorative study. This approach is ideal but some issues aren't easy to workaround, such as (a) The willingness of a school to expose their working Moodle to an experimental system.. (b) The availability of API information and support that is exposed and available to researchers and developers, while WhatsApp and WeChat offer some API information, they are very limited and it was hard to get support. (c) It takes time to develop the required services and an intuitive mobile app that will make the system (mobile app and services) worthwhile to deploy and test in a real classroom environment (LIVE Moodle).

The study employed the results of quantitative and qualitative data from previous surveys. A limited-scope quantitative survey has been done followed by a qualitative data gathering.

An experimental/prototype SMVLE has been developed and deployed and was made available online for evaluation purposes. The SMVLE prototype is the model used in data collection, the experts who participated had a chance to look at the prototype and provided their inputs. These qualitative inputs and all the quantitative data collected then became the basis of the recommendations and conclusions.

\subsection{Data Types and Source}

The study includes quantitative data gathered from various sources. These quantitative data are supported by qualitative data such as the outcome of technical analysis; inputs from various lectures and related materials (e.g. Printed Books, Online Journals, Institutional Websites, Conference Proceedings) provided by world class institutions such as Harvard University, Oxford University, MIT, Purdue, Berkeley, Cambridge. A significant amount of information were also sourced from various Organisations and Companies such as Moodle, Blackboard, Google/Android, Apple, Facebook, Twitter, Frogasia among others.

\section{Findings and Analysis}

This survey covers 125 students and professionals who are currently using or have used one or more VLEs in the past. While no identifiable information about the respondents were collected, 15 nationalities confirmed participation. The purpose of the survey is to understand the VLE usage pattern of the respondents, how much time do they spend on their VLE sites, what do they use to access their VLE, and most importantly their views about Social Networking, Mobile Technology and VLE platforms integration.

Table 1. Survey Sampling

\begin{tabular}{|l|c|}
\hline \multicolumn{1}{|c|}{ Professions/Industry } & Participation \\
\hline $\begin{array}{l}\text { Consulting and Software Development } \\
\text { profession }\end{array}$ & $55 \%$ \\
\hline Current Students (PhD, MSc and BSc) & $20 \%$ \\
\hline IT Recruitment Professionals & $10 \%$ \\
\hline $\begin{array}{l}\text { Lecturer/Students others (public } \\
\text { unconfirmed) }\end{array}$ & $15 \%$ \\
\hline
\end{tabular}

\subsection{Other Surveys and secondary data used}

For the purposes of data triangulation, the following related research papers and surveys and have been consulted.

Engaging students through the $V L E$ - findings from the VLE Usage Survey 2008-2013 by Learning Innovation Network (LIN). 
The Learning Innovation Network (LIN) is the network of academic professionals from higher education that supports academic professional development for staff in the Irish higher education sector, particularly the Institutes of Technology. This survey is a product of multi-institutional group working since 2008; the group has been collecting anonymous data since 2008 from 12 Irish higher institutions over 20,500 student responses.

Barker \& Gossman: The Learning Impact of a Virtual Learning Environment: Students' Views

This survey conducted by Barker \& Gossman in 2013 was given to a particular set of students in a UK University. The survey provides a snapshot of students' views about the use of the VLE and its impact on their learning. The result was collected from 248 second year students at an English sixth form college (SFC). The survey was based on three research questions: whether the use of a VLE has a positive impact on student learning; whether the use of a VLE in teaching and learning helps develop independent learning; and whether the use of a VLE increases students' motivation to learn.

\section{Moodle Survey St. Andrews International School -}

\section{Bangkok Thailand}

The first two surveys were both conducted in the West (Ireland and the UK), for data triangulation purposes, Frederick Never's Moodle survey was also consulted . Frederick is a Digital Learning Integrator, who has been helping educators integrate Moodle in the classroom since 2007. He surveyed 300 students at Saint Andrews International School Bangkok in 2010.

\subsection{Quantitative Survey Results}

The quantitative survey had 15 questions, the goal is to find out what VLE students are using, how do they access/use their VLEs, their experience with their current VLEs and their view of integrating Social Networking and Mobile Technology with VLE.

Table 2. Quantitative Survey Questions

\begin{tabular}{|c|c|}
\hline 1. & $\begin{array}{l}\text { Which of the following VLEs have you used in the } \\
\text { past or currently using? (Select all that Apply). } \\
\text { A. } \quad \text { Moodle } \\
\text { B. } \quad \text { Blackboard } \\
\text { C. } \quad \text { School Own } \\
\text { D. } \quad \text { Other (Please Specify) }\end{array}$ \\
\hline 2. & $\begin{array}{l}\text { What did/do you normally use to access your } \\
\text { school's VLE? } \\
\text { A. } \quad \text { Desktop Computer } \\
\text { B. } \quad \text { Laptop Computer } \\
\text { C. } \quad \text { Tablet } \\
\text { D. Mobile Phone } \\
\text { E. Other (Please Specify) }\end{array}$ \\
\hline 3. & $\begin{array}{l}\text { What did/do you normally use when downloading } \\
\text { slides or other materials from VLE? } \\
\text { A. Desktop Computer } \\
\text { B. Laptop Computer }\end{array}$ \\
\hline
\end{tabular}

\begin{tabular}{|c|c|}
\hline & $\begin{array}{l}\text { C. Tablet } \\
\text { D. Mobile Phone } \\
\text { E. Other (Please Specify) }\end{array}$ \\
\hline 4. & $\begin{array}{l}\text { What did/do you normally use to study your course } \\
\text { materials? } \\
\text { A. Desktop Computer } \\
\text { B. Laptop Computer } \\
\text { C. Tablet } \\
\text { D. Mobile Phone } \\
\text { E. Printed Materials } \\
\text { F. Other (Please Specify) }\end{array}$ \\
\hline 5. & $\begin{array}{l}\text { How would you describe your experience in terms } \\
\text { of Ease of Use? } \\
\text { A. Excellent } \\
\text { B. Good } \\
\text { C. Ok } \\
\text { D. Poor } \\
\text { E. Very Poor }\end{array}$ \\
\hline 6. & $\begin{array}{l}\text { How would you describe your VLE Experience in } \\
\text { terms of User Interface? } \\
\text { A. Excellent } \\
\text { B. Good } \\
\text { C. Ok } \\
\text { D. Poor }\end{array}$ \\
\hline 7. & $\begin{array}{l}\text { Have you tried accessing the VLE via using Tablet } \\
\text { and/or Smartphone? } \\
\text { A. Yes } \\
\text { B. No } \\
\text { C. Skipped }\end{array}$ \\
\hline 8. & $\begin{array}{l}\text { If you answered Yes to Question no. 7, how would } \\
\text { you describe the experience? } \\
\text { A. Very Good } \\
\text { B. Good } \\
\text { C. Ok } \\
\text { D. Poor } \\
\text { E. No Response }\end{array}$ \\
\hline 9. & $\begin{array}{l}\text { How much time did you/do you normally spend } \\
\text { when you are on your school's VLE? } \\
\text { A. < } 30 \text { Minutes } \\
\text { B. > } 30 \text { Minutes to } 1 \text { hour } \\
\text { C. More than } 1 \text { hour } \\
\text { D. Other (Please Specify) }\end{array}$ \\
\hline 10. & $\begin{array}{l}\text { Do you think integrating Social Networking } \\
\text { Features such as a Like Button for students to like } \\
\text { any materials, Share Button to share with a Social } \\
\text { Networking Site, Chat and Comments will improve } \\
\text { your VLE experience? } \\
\text { A. Strongly Agree } \\
\text { B. Agree } \\
\text { C. Neutral } \\
\text { D. Disagree } \\
\text { E. Strongly Disagree }\end{array}$ \\
\hline 11. & $\begin{array}{l}\text { If you like the idea of Integrating Social Networking } \\
\text { features with VLE (e.g. Question 10), which social } \\
\text { networking feature would you like to see } \\
\text { implemented? } \\
\text { A. Like } \\
\text { B. Share } \\
\text { C. Comments } \\
\text { D. Chat } \\
\text { E. Other (Please Specify) } \\
\text { F. No Response }\end{array}$ \\
\hline 12. & $\begin{array}{l}\text { Do you think making VLE more like a Social } \\
\text { Networking Websites (e.g. With Instant Chat } \\
\text { Functionality) will encourage you to login and } \\
\text { interact with your VLE more frequently? } \\
\text { A. Strongly Agree } \\
\text { B. Agree } \\
\text { C. Neutral } \\
\text { D. Disagree } \\
\text { E. Strongly Disagree }\end{array}$ \\
\hline 13. & $\begin{array}{l}\text { Do you think exposing VLE functionalities via a } \\
\text { Mobile App, will encourage you to access the course }\end{array}$ \\
\hline
\end{tabular}




\begin{tabular}{|c|c|}
\hline & $\begin{array}{l}\text { materials more frequently? } \\
\text { A. Strongly Agree } \\
\text { B. Agree } \\
\text { C. Neutral } \\
\text { D. Disagree } \\
\text { E. Strongly Disagree }\end{array}$ \\
\hline 14. & $\begin{array}{l}\text { Do you think exposing Forum via App will } \\
\text { encourage you to actively participate in the class } \\
\text { discussion? (e.g. Reply as you received a } \\
\text { notification of a new message). } \\
\text { A. Strongly Agree } \\
\text { B. Agree } \\
\text { C. Neutral } \\
\text { D. Disagree } \\
\text { E. Strongly Disagree }\end{array}$ \\
\hline 15. & $\begin{array}{l}\text { Do you think VLE Designers has to learn from } \\
\text { Social Networking and embrace the design for } \\
\text { mobile first principle? } \\
\text { A. Strongly Agree } \\
\text { B. Agree } \\
\text { C. Neutral } \\
\text { D. Disagree } \\
\text { E. Strongly Disagree } \\
\text { F. No Response }\end{array}$ \\
\hline
\end{tabular}

Moodle is free and one of the most open VLE platforms available today so it is not surprising that it is widely deployed in Educational Institutions and highly utilised. The result of question 1 shows that $53 \%$ of the respondents have used Moodle, Blackboard is in distance second at $31 \%, 11 \%$ have used school-built VLE and 4\% have used other VLE platforms (see Table 2). The majority of the respondents is either a current student or had obtained a degree from a European school so $60 \%$ using Laptop fits the respondent's profile (e.g. able to buy a laptop). The overwhelming majority, $64 \%$ download VLE materials using their laptop, $27 \%$ use desktop computers, $11 \%$ tablet, none of the 125 respondents downloaded materials on their Mobile Phone (Question 3). Randomly 10 of the survey participants were asked why they had never used Mobile Phone to download school material. Five said they had never accessed VLE using a mobile phone; two said it was more convenient to download via laptop and send to any device later when they need to, and three stated that they didn't like to use their limited data allowance for this purpose. Half of the total respondents (Question 4) use Laptop to study their course materials; while there are about more than $30 \%$ desktop users, surprisingly not all of them, only $14 \%$, use Desktop computer for revision purposes; $10 \%$ use tablet and $26 \%$ still prefer printed materials. VLE users seem to have no problem with the ease of use (Question 5) as 14\% said their VLE are very easy to use (excellent rating). 57\% stated that they can easily accomplish what they need to do (Good rating), 28\% said the experience was ok, their VLE were not easy to use but not so difficult either, seven respondents said the experience was poor and one said it was very poor.

In terms of user interface (Question 6), $48 \%$ thinks the overall design is good but some user interface (UX) redesign could help improve the UI.
$35 \%$ said the UX redesign is strongly recommended and $10 \%$ thinks that the design is poor and a redesigned is needed to meet the current UX standard. However, 9\% disagreed and said the UI is excellent. 90 of the 125 respondents have had accessed their VLE using either a Tablet or a Smartphone, 34 have not and one respondent skipped the question. This result seems to suggest that the idea of using either a Smartphone and Tablet to access a VLE is not far- fetched. While VLE users that used a Tablet or Mobile Phone to access aVLE, didn't seem satisfied with the experience. 17\% said they noticed some display problems (Question 8). $35 \%$ stated that a mobile version would improve the user experience. $22 \%$ had a bad experience. While 34 respondents said, they hadn't used either a tablet or Smartphone to access their VLE, only 32 skipped a related question (Question 7), the other two who haven't tried accessing their VLE on a mobile phone still rated their experience. Table 2 shows that $58 \%$ spends less than 30 minutes on their VLEs, $21 \%$ spends 31 minutes up to an hour, and $21 \%$ spends more than an hour. It 's hard to argue that students are actively engaging with their VLEs and this data seem to agree with the LIN's survey. Most respondents thinks integrating some social networking features to VLE could improve their experience, but interestingly a significant number, $20 \%$, do not seem to like the idea with $7 \%$ strongly opposed it; $28 \%$ is at the moment neutral (Question 10).

It can be noted from Q10 that 25 respondents did not like the idea of integrating social networking features to VLE, perhaps the 25 of the 26 who skipped this question were on the opposition side in Q10 (16 Disagree, 9 Strongly Disagree). The additional one who skipped perhaps realised that none of these features are appropriate for VLE. Comments and Chat seem to be the most popular features that the respondents prefer to see, Like $(21 \%)$ and Share $(20 \%)$ also have strong support. Baker and Grossman [5)] suggested that collaboration tool such as Chat and Forum are underutilised, this quantitative question's purpose is to know what VLE users think about adding collaboration tool such as Instant chat messaging to a VLE. Clearly the majority $(52 \%, 18 \%$ Strongly Agree and 34\% Agree) thinks that it would make students like to visit VLE more frequently, a significant number is uncertain (29\% neutral) and there are still 24 respondents who did not agree with the majority. On the question of making VLE more accessible by exposing its functionalities via mobile app, Question 13 shows that 55\% responded in the positive, $26 \%$ remains uncertain but there is less opposition, this time, only six disagreed and four strongly opposed. Q14 results seem to suggest that VLE users like Forum but unable to utilise them perhaps due to the accessibility of the forum, as a 
staggering $63 \%$ agreed that it would improve their participation in collaborative learning specifically Forum, $32 \%$ is not sure and six people did not agree. The majority $(61 \%)$ thinks that VLE designers have to learn from Social Networking and make Mobile devices a priority when designing VLEs, $23 \%$ are neutral, $7 \%$ disagreed and $12 \%$ skipped the question.

\subsection{Qualitative Research Result Summary}

To further validate the result of the Quantitative data, 15 people were further interviewed, all of whom had used one or more VLE and had significant industry experience.

Table 3. Qualitative Survey Participants

\begin{tabular}{|l|}
\hline \multicolumn{1}{|c|}{ Participants } \\
\hline 15 Professionals from Consultancy, Software Development \\
and Educational Institutions and with average Industry \\
Experience of 8.5 years. \\
\hline
\end{tabular}

Table 4. Qualitative Survey Participant Sampling

\begin{tabular}{|l|c|}
\hline Professions/Titles & Percentage \\
\hline 5 - Senior Java Developers & $33.3 \%$ \\
\hline 2 - Managers & $13.3 \%$ \\
\hline 1 - Senior Manager & $0.7 \%$ \\
\hline 4 - Front End Developers & $26.7 \%$ \\
\hline 2 - IT Instructors/Moodle & $13.3 \%$ \\
\hline Administrator & \\
\hline 1 - UX Designer & $0.7 \%$ \\
\hline
\end{tabular}

The quantitative questions on my guide questionnaire are as follows:

Question \#1: What most important features of VLEs should be exposed to a Mobile App?

Answers (summarised):

From usability perspective, less is more and the more complicated a system become, the fewer people would use it. Learning curve has to be managed in order for a system or an app to be successful, with more than 4 Billion Apps available online. The Mobile App will be designed to be simple while offering students access to the features they need.

Top answers are. Grades, Lecture Materials, Forum, Assignments. General views people, students in particular shouldn't be bombarded with too much information, in terms of what people need from VLE, it is to access the lecture material, participate in collaborative learning, access assignment/continuous assessment instructions and get the grades; electronic homework and submission would also help.

Question \#2: What do you think of integrating Social Networking with VLEs?

\section{Answers (summarised):}

10 Said it's a good Idea - It will be more fun, easy to access, open cross-school enrolment, teachers will get instant feedback, students will engage more, among others.

2 were neutral -There are pros and cons, the most important benefit is perhaps integrating social networking would revitalise the platform and encourage students to use collaborative learning tools that are currently under-utilised. One of the biggest concern is we might be unnecessary putting power to students. Social Networking is such a powerful force; it could destroy reputation so it might be used to force teachers to be unnecessarily likeable.

3 had reservations - Students are supposed to be working in school, the worry is they might treat VLE as just another social networking, they might abuse some of the powerful features, e.g. Likes and Comments.

Question \#3: While the benefits of having a Portable VLE seem to be overwhelming, can you think of any reasons why VLE functionalities should not be exposed to a Mobile App? Answers (summarised):

Data Confidentiality and Security Issues were mentioned. How to secure the data, will it be stored in the mobile app, what encryption will be applied during transmission and once the data arrived the device.

Question \#4: If you agree that integrating Social Networking features such as Likes, Comments, Share, Instant Messaging, among other features to a VLE would make students like to Access VLE more often, can you think of any reasons why we shouldn't do this?

Answers (summarised):

VLE is supposed to be dull and formal so it was designed that way. Students are expected to do work and trained hard and not having fun chatting with friends, mocking lecture materials via comments, forcing some teachers to be someone they are not for the purposes of getting likes and positive comments, such power might interfere with academic decision e.g. grading.

Question \#5: From a technical point of view, what can you say about using Social Plugins, such as Facebook API, Twitter among others. Answer (summarised):

- Many come with very limited support

- They break over time; there is no Warranty Provided 
- Social Plugins are in early development stages and changes all the time

-There is no standard; company dictates the standard and decide how to do things

Question \#6: What best practices in designing UI could you offer?

Answers (summarised):

- Know why you are doing things, Minimise user tasks, Familiar, no or little learning curve

- User colour combination correctly, it is not just for design aesthetics but also for accessibility

- Design for User Convenience not first for Developer's convenience

- Usability Testing and User Profiling

Question \#7: Is it true that collaborative tools such as Forum, Chat among others are underutilised?

Answers (summarised):

- Yes, some students access Forums when CA deadline is near (mostly less than a week)

- No one has used Chat, not enabled by default

Question \#8: Have you heard about a Social Mobile VLE or SMVLE? If you have, from whom or where and what was it about?

Answer (summarised):

- No, this is the first time

- Frog is a Social Networking for School; it's a VLE but they do not refer to it as a Social Mobile VLE

Question \#9: Do you think Mobile Technology had already matured? Let's talk about Android or iOS, using the CMMI model what can you say about the level of Maturity of Android and iOS platforms? Is CMMI model applicable or is there a better model we could use to gauge mobile platform maturity.

Answers (summarised):

- Level 3 - Defined, Processes are well characterised and understood. Processes, standards, procedures, tools, etc. are defined at the organisational level. Proactive

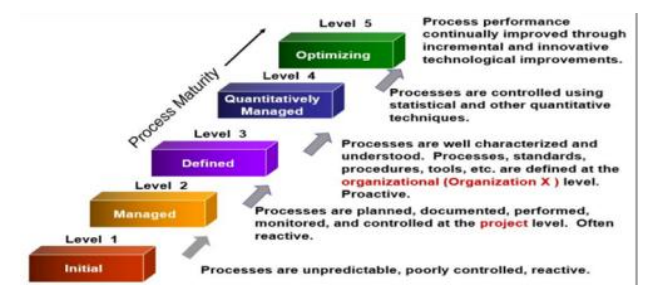

Figure 1. Capability Maturity Model (CMMI). Taken from: (http://www.modernrequirements.com)
Question \#10: Do you think collaborative activities and providing both learners and educators better collaboration tools could influence learning?

Answers (summarised):

Yes, collaboration is an accepted learning strategy. Not just in the academia but also in the industry, that is why collaboration tools are very popular; there's quite a number of them it is also a Billion-dollar business.

\section{Discussion}

VLE, Social Networking and Mobile Technology are disruptive platforms. VLE redefined distance education and unlocked many possibilities, including making education accessible to students who cannot attend traditional classroom-based courses, allowing for better social inclusion. Social networking, a multi-billion-dollar industry, is a dominant platform today. It 's hard to quantify the influence of social networking, for instance, the so-called Arab spring is believed to have been fuelled by social networking sites [17]. In this case, some group of people were able to advance their causes by influencing other people to act or do something via social networking sites such as Twitter and Facebook and partly they succeeded. The introduction of iPhone in 2007 invigorated interests in mobile technology, there is a Mobile App for almost anything. We have now entered the social-mobile era and for VLE to stay relevant, in terms of platform utilisation, they must adapt

\subsection{Making VLE more accessible to students in today's social-mobile centric world}

The review of related statistics reveals the heavy utilisation of mobile devices in accessing online services. Furthermore, relevant research in the review of related literature uncovers the younger generations' addictive behaviour toward mobile devices. These quantitative data, mobile Internet traffic and youths' mobile device activity corroborates: mobile devices are an effective vehicle to reach them [younger generations]. Social Network users' engagements with Social Networking Sites is astronomical. $70 \%$ of Facebooks users connects to the site on a daily basis. As of March 2016, Facebook has 1.09 billion daily active users on average and 989 million of this are mobile users [18], these numbers are unprecedented.

Previous research shows that students view VLEs favourably [5] [7] [8] and incorporating social networking elements such as the ability to Like, Share and Comment on a material and exposing VLE functionalities via mobile app will encourage them to access their course materials more frequently. The 
quantitative data gathered from professionals also agreed that mobile app would high likely increase students' engagements with their VLEs because it will make VLE more portable.

\subsection{Moodle VLE services that can be exposed to a third party/Mobile client.}

There is a number of VLEs available in the market today; Uniservity, Frog, Blackboard, Moodle among others. Since its commonplace to a use Moodle in Ireland (e.g. UCD, TCD, NCI, ITT classmates/colleagues) and because Moodle is by far the most open VLE platform, Moodle was chosen as our prototype environment. Some of the Moodle Services that are currently available to developers and can be exposed to the clients in Figure 2.

Table 6. Partial List of Moodle Services that is exposed to Developers

\begin{tabular}{|c|c|}
\hline Services & Description \\
\hline $\begin{array}{l}\text { mod_forum_add_dis } \\
\text { cussion }\end{array}$ & $\begin{array}{l}\text { Add a new discussion into an existing } \\
\text { forum. }\end{array}$ \\
\hline $\begin{array}{l}\text { mod_forum_add_dis } \\
\text { cussion_post }\end{array}$ & $\begin{array}{l}\text { Create new posts into an existing } \\
\text { discussion. }\end{array}$ \\
\hline $\begin{array}{l}\text { core_user_get_users } \\
\text { _by_field }\end{array}$ & $\begin{array}{l}\text { Retrieve users information for a } \\
\text { specified unique field - If you want to } \\
\text { do a user search, use } \\
\text { core_user_get_users() }\end{array}$ \\
\hline $\begin{array}{l}\text { core_grades_get_gra } \\
\text { des }\end{array}$ & $\begin{array}{l}\text { Returns student course total grade and } \\
\text { grades for activities. This function does } \\
\text { not return category or manual items. } \\
\text { This function is suitable for managers or } \\
\text { teachers not students. }\end{array}$ \\
\hline $\begin{array}{l}\text { core_course_get_cou } \\
\text { rse }\end{array}$ & Return course details \\
\hline $\begin{array}{l}\text { Mod_assign_ger_assi } \\
\text { gnment }\end{array}$ & $\begin{array}{l}\text { Returns the courses and assignments for } \\
\text { the users capability }\end{array}$ \\
\hline $\begin{array}{l}\text { enrol_self_enrol_use } \\
\mathbf{r}\end{array}$ & $\begin{array}{l}\text { Self-enrol the current user in the given } \\
\text { course. }\end{array}$ \\
\hline
\end{tabular}

\subsection{The existing gaps in the VLE platform}

While reviewing existing literature on the topic, several critical issues surfaced. The following are some gaps that require attention for VLEs to take advantage of the popularity of Social Networking and Mobile Technology.

\subsubsection{Standardization Body}

Web Technologies are becoming better every day, integration of various web technologies is becoming easier and predictable. Perhaps one of the reasons is because there is an expert group or standard organisations working to establish standards and compliance. One of them is the World Wide Consortium (W3C) which is overseeing the development of HTML, CSS, and Document Object Model. Another famous one is The Internet
Engineering Task Force (IE) which defines Internet Infrastructure including protocols such as FTP, TCP/IP and format of email addresses. The European Association for Standardizing Information and Communication Systems (ECMA), is the expert group that looks after many information based technology standards including ECMAScript, the standard version of JavaScript. There are many other organisations such as ANSI, ISO, No expert group that looks after VLE Platform/Technology Standardisation could be identified. The E-Learning Industry has the Shareable Content Object Reference Model (SCORM), a standard that provides guidelines to E-learning software developers on how to develop a cross-platform learning app. But at the time of this writing, there is none for VLE developers, so integration between one another (e.g. Blackboard and Moodle) though possible, would require a lot of effort. Also, developers need to know both systems to create client app that supports multiple VLEs; this does not just need more development effort but also could unnecessary bloat the mobile client (different code for the same functionality). This issue is perhaps the reason why there is not a single cross VLE mobile app available to date: developing one is either time consuming if not impossible at all.

\subsubsection{Industry Support and Innovation}

VLE remains to be an academic tool, something not profitable or has less or no strategic value for many of today's Internet giants. VLEs is not getting enough support from the likes of Facebook, Apple (who has Apple University); Oracle, who owns MySQL (Moodle's DB) and others. If VLE gets a solid backing from one of these corporate giants' VLE development will accelerate. A governing body will rise, API support will be much better, Integration between VLEs will be much easier due to various APIs that will come from different parts of the world, and finally cross-platform Mobile App will become available, plenty of them.

Perhaps the thinking of VLE designers is that learning platforms are supposed to be formal, neutral looking and UX design does not matter because they don't have to please their audience: the students and teachers. While this is a valid argument, research shows that this is not the case. Dr Jacob Nielsen, a usability expert, also made a compelling argument about usability; he stated that usability is the King of the Web [19]. Students and teachers could decide to use VLE less often or not at all if they find it difficult to use, e.g. they can't easily accomplish a task, hard to access, time-consuming or simply monotonous, they have the sole power to use it or not. The purpose of building something is for people to use it, therefore if the very people you are targeting to use your creation won't, then there is no point of creating it in the first place. Both the qualitative and 
quantitative data agree that Innovation is necessary for VLE to encourage users to log in and engage with the platform more frequently.

\section{SMVLE Prototype}

The prototype is a partial implementation of the proposed SMVLE, while the prototype proves that social networking, mobile technology and VLE integration is possible, at the moment many components in the proposed VLE are missing as they [unimplemented components] are not within the scope of this study.

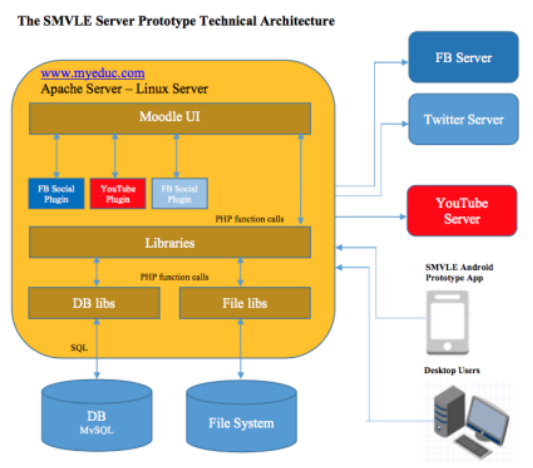

Figure 2. Server Technical Architecture

Social plugins from Facebook (FB), Twitter and YouTube were integrated to give some social networking features with Moodle. Other social networking features implemented are Likes, Shares, Comments, YouTube Video, Tweets and Twitter Widget.

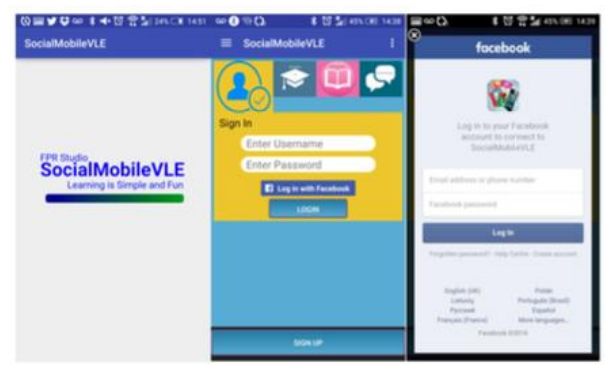

Figure 3: Client Prototype

While designing the client app, the Social-Mobile VLE app, user feedback was gathered and used in the implementation of the prototype. The final design of the prototype is based on user comments and recommendation. Figure 3 shows the splash, regular login and social network users login screen. The social network login is the implementation of the Leverage Optimisation Strategy (LOS). Many other social networking sites offers authentication service for third party, Facebook was chosen because it is by far the most popular social networking platform to date.

\section{Summary and Conclusion}

Over the last few decades, we experienced problems with information overload, too many information from various sources that was hard to consume and process. In the last few years, we regularly hear the term Big data, problems with data volume, velocity, variety. Many technology companies went on data mining, harvesting and sharing like crazy and now they have reached the point where traditional computer system can no longer handle the enormous amount of data they have collected. Fortunately, because this is a big guy's problem, they have found a solution, in the form of NoSQL DB Technologies, Data Analytics/Business Intelligence tools among others. In the academia, while VLEs such as Moodle, offer a wide variety of services including collaboration tools, research shows that many VLE functionalities are underutilised, particularly the collaboration tools. It seems like for students logging into their VLE is hard work as they only connect to their VLE at least once a week for under 30 minutes, compared to $51 / 2$ hours social media users spent on social media sites on a daily basis [20]. With all the intuitive services currently available to the consuming public, VLE users included, this is not surprising. However, the possible declining students interest in interacting with VLEs is alarming and rethinking VLE design and the services it provides is a timely issue.

\subsection{What is the best way to make VLE more accessible to students in today's social-mobile centric world?}

The quantitative and qualitative data gathered as part of this study agreed, integrating mobile technology by creating a mobile VLE app (e.g. Android App) will make VLEs accessible to many people who use Mobile Devices to access online services. Dr Jacob Nielsen, a user advocate, specialising in web usability, stated that usability is the King of the Web and the person who uses the mouse could solely decide where to go [19]. Apparently there are many other more exciting places on the web than the student's VLE, so VLEs has to reinvent itself to compete successfully for user's attention. Both the qualitative and quantitative data corroborates: going social and mobile is the right direction for VLEs.

7.2. What current VLE services can be exposed to a third party/Mobile client (Moodle being the most popular and accessible one as an example)?

A number of VLEs were evaluated, and none where as popular and less restrictive as Moodle. 
Aside from Moodle is entirely free and does not come with license restriction, it is well documented and maintained. The Social-Mobile VLE (SMVLE) Prototype is based on Moodle. Moodle provides various services that are open to third-party applications. It exposes the course content, assignments, calendar, forum, grades and other information via various RESTful services. Developers can virtually build a Mobile App exposing most if not all services that a Moodle Web Based version provides.

\subsection{Will making VLE more accessible via Mobile Social Networking improve VLE utilisation (e.g. will students engage in Forum discussions more often?)}

Based on the quantitative survey in Chapter 3 above, the majority said that making VLE social (having social networking elements) and mobile (exposing features via Mobile App) will encourage them to access VLEs more frequently. The qualitative interviews conducted also support this quantitative analysis. While the experts raised some valid concerns about incorporating social networking elements to a VLE, they agreed that VLE users would welcome this development because it provides them [students] both convenience (access VLE services via Mobile App) and social networking influence/power (ability to Like and Comment on Lecture Materials)

\subsection{The need to leverage Social Networking and Mobile Technology in designing future generation VLEs and improving the popular ones}

Research shows that both social networking and mobile technology are formidable communication tools, learning is about well, in fact, revolves solely around communication. People use both social networking and mobile technology all the time and everywhere, it is dreadful to go against the current, in a democracy nobody can win against the majority. VLE has to go social and mobile to maintain its relevance amongst students.

\subsection{The need to employ UX in VLE design}

In the world where modern web technologies had significantly improved, creating beautiful websites is now like a walk in the park. With the availability of many JavaScript Libraries such as Bootstrap.JS, React.JS, Angular.JS, JQuery, Node.JS and all the tools that is now available to Front-End Designers and UX professionals, designing highly attractive websites no longer cost an arm and a leg and does not take a lot of time either. Adding Bootstrap on your project, for instance, will let you use the default CSS and configuration transforming your site to a Modern Website instantly without even touching anything. Angular.JS will allow you to build Single Page Application or SPA, making development much quicker as you no longer need backend services to do calculations or implement business logic that Angular.JS could handle at the client side. JQuery simplifies JavaScript so you no longer have to write a lot of code. In summary, User Interface design also known as UX design is becoming a standard requirement, in fact, it is now a common practice, even small companies has employed UX and used many of the new modern web design technologies.

The competition for relevance is multidimensional, VLE has to deliver the services which are expected from it and at the same time it has to look fresh and interesting.

\subsection{The need for a Social-Mobile VLE}

Why SMVLE, the user engagement with social networking sites is astronomical, $70 \%$ users or an astonishing 1.09 billion daily Facebook active users is unprecedented [18]. VLE users on the other hand $\log$ into their VLE once a week and only stays for less than 30 minutes. Clearly, there's a problem with VLE user engagements. Mobile devices are becoming cheaper, more reliable, and versatile. People use mobile devices all the time to access internet services, and this trend will continue in the foreseeable future.

The goal of SMVLE is to leverage the profound influence of social networking on the younger generation and the increasing accessibility and popularity of mobile devices among the general public to make VLE more accessible.

\subsection{Future Research: The need for VLE Design Standardisation for cross VLE platform compatibility}

The second-wave feminist of 1960's fought for Educational liberty, education was and should always be an important issue not just for the feminist but for everyone. The topic about equal access to education is not new, in the US during Bush administration one of the most important issues they addressed was the no child left behind Act, it was passed in 2001 and now known as the "The No Child Left Behind Act of 2011". Perhaps a more interesting question is, considering that the majority of the countries in the world are members of the United Nations, regardless of student's nationality is it a fundamental right of every student to have access to any schools in the world (e.g. Harvard, Cambridge, Oxford, TCD, UCD)? The other question is about the technical aspect, if every 
student is, in fact, has the right to learn from the best universities, how can this be done, considering the geographical location and the cost involved, would VLE Design Standardisation for cross VLE platform helps?

\section{References}

[1] Rante, F., 2016. The Convergence of Social Networking, Mobile Technology and Virtual Learning System: Exploring the effect of making Virtual Learning Environments more accessible to students via Mobile Social Networking. MSc. University College Dublin.

[2] Beetham, H. and Sharpe, R. eds., 2007. Rethinking Pedagogy for a Digital Age - Designing and delivering elearning. New York: Routledge.

[3] Polisca, E., 2006. Facilitating the Learning Process: An Evaluation of the Use and Benefits of a Virtual Learning Environment (VLE)-enhanced Independent Languagelearning Program (ILLP). Calico Journal, e-journal 23 (3).

[4] Kosack, S., 2012. The Education of Nations. Oxford: Oxford University Press.

[5] Barker, J., Gossman, P., 2013. Barker \& Gossman: The Learning Impact of a Virtual Learning Environment: Students' Views. Teacher Education Advancement Network Journal.

[6] Basit, T.N. and Tomlinson, S. eds., 2014. Social Inclusion and Higher Education. Bristol: The Policy Press.

[7] Nevers, F., 2010. Moodle Survey. Iteachwithmoodle, [online]. [Accessed 6 March 2017].

[8] Learning Innovation Network, 2013. Sustainable Models of Student Engagement - Rhetoric or Achievable?. 6th Annual Learning Innovation Network Conference. Dublin, Ireland, 17 October 2013. Dublin: LIN.

[9] Microsoft, 2015. Attention Spans. Canada: Microsoft Corporation. [Accessed 25 February 2016].

[10] Ferriman, J., 2014. Why Moodle Is Becoming Irrelevant. LearnDash Learning and Colloboration blog, [blog] 16 June. [Accessed 19 January 2016].

[11] Wooding, J., 2012.What's wrong with Moodle?. jwgecko RTO - Training \& Technology blog, [blog] 21 January. [Accessed 19 January 2016].

[12] Kuss, D., Griffiths, M., 2011. Online Social Networking and Addiction - A Review of the Psychological Literature. International Journal of Environmental Research and Public Health, 8(9).

[13] Buffardi, L., Campbell, K., 2008. Narcissism and Social Networking Web Sites. Personality and Social Psychology Bulletin, [e-journal] 34 (10).

[14] ExpovistaTV, 2015. Satya Nadella Keynote Speech at WPC 2015, WPC [Accessed 27 February].
[15] Cheng, R., 2014. Farewell Nokia: The rise and fall of a mobile pioneer. CNET, Access 16 Feb. 2016].

[16] Meyers, J., 2011. Watch The Incredible 70-Year Evolution Of The Cell Phone. Business Insider, [online] 6 May. [Accessed 5 February 2016].

[17] Wolman, D., 2013. Facebook, Twitter Help the Arab Spring Blossom. Wired.

[18] Facebook, 2016. Facebook Newsroom - Statitstics. [Accessed 10 April 2016].

[19] Nielsen, J., 2000. Designing Web Usability: The Practice of Simplicity. New York: New Riders Publishing.

[20] Keyes, J., 2012. Social Software Engineering: Development and Collaboration with Social Networking. Boca Raton FL: CRC Press.

[21] AG Campbell, K Santiago, D Hoo, E Mangina "Future mixed reality educational spaces" Future Technologies Conference (FTC), 2016. 